\title{
Optimization of Bioactive Compounds Production by Endophytic Chaetosphaeronema sp. (KY321184) Using Experimental Design Method
}

\author{
Mohamed E. Osman ${ }^{(1)}$, Ahmed A. El- Beih ${ }^{(2)}$, Om-Kalthom H. Khatab ${ }^{(1)}$, Saad \\ A.M. Moghannem ${ }^{(3)}$ and Nashwa H. Abdullah ${ }^{(1) \#}$ \\ (1)Botany and Microbiology Department, Faculty of Science, Helwan University, \\ Helwan, Egypt; (2)Chemistry of Natural and Microbial Products Department, \\ Pharmaceutical Research Industries Division, National Research Centre, Cairo, \\ Egypt; (3)Botany and Microbiology Department, Faculty of Science, Al Azhar \\ University, Cairo, Egypt.
}

\begin{abstract}
THE PRODUCTION of bioactive compounds by endophytic Chaetosphaeronema sp. (KY321184) has been optimized using the experimental design methods. Among seven fermentation parameters, Plackett-Burman design revealed that potato extract concentration, glucose concentration and inoculum size are three significant variables positively affecting the production process. The levels of these variables have been optimized using Box-Behnken design. The best productivity was estimated under potato extract concentration, glucose concentration and inoculum size of $190 \mathrm{gL}^{-1}, 15 \mathrm{gL}^{-1}$ and 5 fungal discs $(0.8 \mathrm{~cm}$ diameter), respectively. The model was validated experimentally, and it showed a deviation error of $4.3 \%$ and 5.3\% from the predicted values of Design Expert's model and the Excel solver, respectively, which considered as an acceptable error. Moreover, it has been observed that, trails of PlackettBurman design stimulated the production of different compounds and one of them is produced in a partially pure form. This observation suggests that, this type of experimental design not only can be employed for optimization purpose but also may represent a method to modify the production pattern of bioactive compounds in a trial to obtain them in a partially pure form to save the cost and effort exerted in the purification process.
\end{abstract}

Keywords : Chaetosphaeronema sp. KY321184, Endophytic, Bioactive compounds, Statistical optimization, Plackett-Burman, Box-Behnken.

\section{Introduction}

Endophytic fungi can be defined as fungi that colonize living plant tissues without causing any immediate overt negative effects (Stone et al., 2004). Plant endophytic fungi have been recognized as an important and novel source of natural bioactive products where endophytes synthesize many metabolites to compete with epiphytes and pathogens to colonize the host, also to regulate the host metabolism in a balanced association (Chandra, 2012). Recently, many endophytes have been reported to produce novel antibacterial, antifungal, antiviral, anti-inflammatory and antitumor compounds (Kumar et al., 2013). Optimization of fermentation conditions for endophytic fungi represents an important method to overcome the supply problems of such compounds and may play a role to develop an economically effective production method. Optimization process is traditionally performed by the one factor at time approach (OFAT) (Anderson \& Whitcomb, 2004). In such technique one variable is studied at a time while the other variables are kept constant (Stowe $\&$ Mayer, 1966). This method is a time-consuming method where the effect of only one variable is monitored at one time thus the variables must be optimized one by one (Zacharis \& Tzanavaras, 2004). Moreover, such approach cannot detect the interaction of factors which likely found in many fermentation processes. Therefore, quality professionals prefer the use of statistically-based methods known as design of experiment (DOE) (Anderson \& Whitcomb, 2004). These methods not only investigate the main effect of a large number of factors in a relatively small number of experiments, but also detect the interaction between factors (Quinn \& Keough, 2002 and Rakić 
et al., 2012). Experimental designs for optimization process begins with a screening design to evaluate the vital few factors affecting the process from a large number of factors, for example; PlackettBurman (PB) experimental design. (Anderson \& Whitcomb, 2004 and Rakić et al., 2012). Such design only determines the main effect of factors but the information about factors interaction is missing (Rakić et al., 2012). This step is followed by the optimization design which generates a response surface map and moves the process to the optimum location (Anderson \& Whitcomb, 2004). Moreover, it predicts the interaction effects among the variables, for example; Box-Behnken (BB) design ( $\mathrm{Li}$ et al., 2008). Finally, the design must be validated by a confirmatory run to ensure that the model produces accurate predictions for the responses of interest (Anderson \& Whitcomb, 2004).

In this study the production of bioactive compounds by endophytic Chaetosphaeronema sp. (KY321184) has been optimized using the experimental designs methods in a trail to produce such compounds by an economically effective method.

\section{Materials and Methods}

\section{Microorganism}

The fungus under this investigation is an endophytic fungus isolated from Nepeta septemcrenata bark samples which have been collected from Saint Catherine, South Sinai, Egypt, in May 2014 by the method described by Garyalis et al. (2013).

\section{Assessment of bioactive compounds production \\ Standard fermentation process}

Four fungal discs (disc diameter $=0.8 \mathrm{~cm}$ ) were inoculated to $75 \mathrm{ml}$ potato dextrose broth medium on $250 \mathrm{ml}$ conical flask and incubated at $25^{\circ} \mathrm{C}$ for two weeks under static conditions.

\section{Extraction method}

The culture medium was filtered by Whatman filter paper no. 1 to separate the mycelium. The filtrate and the grinded mycelium were extracted by equal volume methylene chloride, then separated and evaporated at $35^{\circ} \mathrm{C}$ using rotary vacuum evaporator. The dry residues were re-dissolved in minimal volume of methanol to collect the crude extracts.
Assessment of bioactive compounds contents

The crude extracts were tested for their antibacterial activity against Staphylococcus aureus ATCC 25923 to evaluate the bioactive compounds production. The crude extracts were dissolved in $6 \mathrm{ml}$ acetone and $50 \mu 1$ were inoculated in $2 \mathrm{ml}$ nutrient broth inoculated with $100 \mu \mathrm{l}$ bacterial suspension (0.5O.D), then incubated at $37^{\circ} \mathrm{C}$ for $24 \mathrm{~h}$. The antibacterial activity was evaluated by measuring the density of bacterial growth at $600 \mathrm{~nm}$ and calculation of the inhibition percent as following :

$\%$ of inhibition $=(\mathrm{Ab}$. of control $-\mathrm{Ab}$. of sample/Ab. of control) $\times 100$.

Note: Control was inoculated with $50 \mu$ acetone instead of the inoculum of extract.

Experimental designs for optimization of bioactive compounds production

Screening for the vital factors affecting the bioactive compounds production by PlackettBurman (PB) experimental design

Seven variables representing the basal medium components and fermentation conditions were tested at low (-1) and high $(+1)$ levels as shown in Table 1. Fifteen runs were organized according to the Plackett-Burman design as indicated in Table 2. This design matrix contains three replicated center points to avoid error. All the trials were performed in duplicates using $250 \mathrm{ml}$ Erlenmeyer flasks and the final data were calculated as the mean of duplicate.Plackett-Burman experimental design is based on the first-order polynomial model:

$$
\mathrm{Y}=\beta_{0}+\sum \beta_{\mathrm{i}} \mathrm{X}_{\mathrm{i}}
$$

where $\mathrm{Y}$ is the response, $\beta_{0}$ is the model intercept, $\beta_{\mathrm{i}}$ is the linear coefficient, and $X_{\mathrm{i}}$ is the level of the independent variable (Talukdar et al., 2016). The variables significant at $95 \%$ level $(\mathrm{P}<0.05)$ were considered to have significant effect.

Optimization of bioactive compounds productions by response surface methodology using Box-Behnken design (BBD)

To enhance the production of the bioactive metabolites, the three most significant factors positively affecting the production have been selected according to Plakett-Burman experimentand optimized by employing BoxBehnken design. These factors were studied at three different levels, low (-1), high (+1) and 
intermediate (0) (Table 3). The experiment was carried out in fourteen trials (Table 4) with two central points. All the trials were performed in duplicates using 250ml Erlenmeyer flasks and final response value was calculated as the mean of duplicate. Results were fitted with a secondorder polynomial equation. The general form of the second-order polynomial equation is:

$$
Y=\beta_{0}+\Sigma \beta_{i} X_{i}+\Sigma \beta_{i j} X_{i} X_{j}+\Sigma \beta_{i i} X_{i}^{2}
$$

where $Y$ is the predicted response, $\beta_{0}$ is the intercept term, $\beta_{i}$ is the linear coefficient, $\beta_{i j}$ is the quadratic coefficient, $\beta_{i i}$ is the interaction coefficient, and $X_{i} X_{j}$ represent the independent variables (Jose et al., 2013). Regression analysis was performed on the data obtained using software package "Design Expert Software" (Version 7.0) and confirmed by Microsoft Excel 2016 (Moghannem et al., 2017). The accuracy of polynomial model equation was evaluated by determination of $\mathrm{R}^{2}$ and adjusted $R^{2}$. The fitted polynomial equation was expressed in the form of three-dimensional response surface plots. The
Design Expert numerical optimization method and Excel solver were employed to optimize the level of each variable for maximum response.

\section{Experimental validation}

To confirm the model, one predicted solution for maximum bioactive compounds production which has been estimated by the Design Expert numerical optimization and the Excel solver was selected as a check point and tested experimentally to calculate the percent of deviation.

\section{Chemical evaluation of $P B$ trails products}

Identity and purity of compounds produced by different PBD trails has been investigated by TLC, HPLC and $\mathrm{H}^{1} \mathrm{NMR}$. HPLC was carried out for trail number 15 , where $60 \mu \mathrm{g}$ dissolved in acetone was injected in reversed phase column (ZORBAX SB-C18 $5 \mu \mathrm{m}, 250 \times 9.4 \mathrm{~mm}$ ), eluted with methanol:water $1: 1$ and detected at $\lambda=254$ and $280 \mathrm{~nm}$. $\mathrm{H}^{1} \mathrm{NMR}$ for trail number 15 was carried out in $\mathrm{CDCl} 3$ using a BRUKER $400 \mathrm{MHz}$ in Microanalytical Unit -Faculty of Pharmacy, Cairo University, Egypt.

TABLE 1. Factors and coded levels examined in the Plackett-Burman design experiment.

\begin{tabular}{lccccc}
\hline Factor & Symbol & Units & Low level (-1) & High level (+1) & Central point \\
\hline Potato extract conc. & $\mathrm{A}$ & $\mathrm{gL}^{-1}$ & 0 & 200 & 100 \\
Glucose conc. & $\mathrm{B}$ & $\mathrm{gL}^{-1}$ & 0 & 20 & 10 \\
Temperarure & $\mathrm{C}$ & ${ }^{\circ} \mathrm{C}$ & 20 & 28 & 24 \\
$\mathrm{pH}$ & $\mathrm{D}$ & - & 4.5 & 8.5 & 6.5 \\
Incubation period & $\mathrm{E}$ & Week & 1 & 3 & 2 \\
Inoculum size & $\mathrm{F}$ & Fungal disc* & 2 & 6 & 4 \\
Aeration & $\mathrm{G}$ & $\mathrm{ml} / 250 \mathrm{ml}$ flask & 25 & 75 & 50 \\
\hline
\end{tabular}

*Fungal disc Diameter $=0.8 \mathrm{~cm}$

TABLE 2. Plackett-Burman design matrix for evaluating significant factors affecting bioactive compounds production by Chaetosphaeronema sp. (KY321184).

\begin{tabular}{|c|c|c|c|c|c|c|c|c|c|c|c|c|}
\hline $\begin{array}{l}\text { Trial } \\
\text { no. }\end{array}$ & $\mathbf{A}$ & $\mathbf{B}$ & $\mathrm{C}$ & D & $\mathbf{E}$ & $\mathbf{F}$ & G & $\mathbf{H}^{*}$ & $\mathbf{J} *$ & $\mathbf{K}^{*}$ & $\mathbf{L}^{*}$ & $\begin{array}{c}\text { Response } \\
\text { (\% inhibition) }\end{array}$ \\
\hline 1 & 0 & 0 & 0 & 0 & 0 & 0 & 0 & 0 & 0 & 0 & 0 & 89.7 \\
\hline 2 & 0 & 0 & 0 & 0 & 0 & 0 & 0 & 0 & 0 & 0 & 0 & 85.3 \\
\hline 3 & 1 & 1 & 1 & -1 & -1 & -1 & 1 & -1 & 1 & 1 & -1 & 3.6 \\
\hline 4 & -1 & -1 & -1 & -1 & -1 & -1 & -1 & -1 & -1 & -1 & -1 & 7.8 \\
\hline 5 & 1 & 1 & -1 & -1 & -1 & 1 & -1 & 1 & 1 & -1 & 1 & 90.6 \\
\hline 6 & 1 & -1 & -1 & -1 & 1 & -1 & 1 & 1 & -1 & 1 & 1 & 23.1 \\
\hline 7 & 0 & 0 & 0 & 0 & 0 & 0 & 0 & 0 & 0 & 0 & 0 & 85.3 \\
\hline 8 & -1 & 1 & -1 & 1 & 1 & -1 & 1 & 1 & 1 & -1 & -1 & 7.8 \\
\hline 9 & 1 & -1 & 1 & 1 & -1 & 1 & 1 & 1 & -1 & -1 & -1 & 2.9 \\
\hline 10 & -1 & 1 & 1 & 1 & -1 & -1 & -1 & 1 & -1 & 1 & 1 & 2.6 \\
\hline 11 & -1 & -1 & 1 & -1 & 1 & 1 & -1 & 1 & 1 & 1 & -1 & 4.6 \\
\hline 12 & 1 & 1 & -1 & 1 & 1 & 1 & -1 & -1 & -1 & 1 & -1 & 8.1 \\
\hline 13 & -1 & 1 & 1 & -1 & 1 & 1 & 1 & -1 & -1 & -1 & 1 & 35 \\
\hline 14 & -1 & -1 & -1 & 1 & -1 & 1 & 1 & -1 & 1 & 1 & 1 & 9.4 \\
\hline 15 & 1 & -1 & 1 & 1 & 1 & -1 & -1 & -1 & 1 & -1 & 1 & 16.8 \\
\hline
\end{tabular}

*: H, I, J, K are Dummy variables. 
TABLE 3. Levels of the factors selected for Box-Behnken design.

\begin{tabular}{lcccc}
\hline Factor & Units & Low level (-1) & High level $(+\mathbf{1})$ & $\begin{array}{c}\text { Intermediate level } \\
(\mathbf{0})\end{array}$ \\
\hline Potato extract conc. & $\mathrm{gL}^{-1}$ & 0 & 200 & 100 \\
Glucose conc. & $\mathrm{gL}^{-1}$ & 0 & 20 & 10 \\
Inoculum size & Fungal disc & 2 & 6 & 4 \\
\hline
\end{tabular}

*Fungal disc diameter $=0.8 \mathrm{~cm}$.

TABLE 4. Box-Behnken design matrix for optimizing bioactive compounds production by Chaetosphaeronema sp. (KY321184).

\begin{tabular}{lcccc}
\hline Trail no. & Potato extract conc. & Glucose conc. & Inoculum size & Response (\% inhibition) \\
\hline 1 & 0 & -1 & 1 & 30.9 \\
2 & -1 & -1 & 0 & 0.15 \\
3 & 1 & 0 & -1 & 88.7 \\
4 & -1 & 0 & -1 & 8.2 \\
5 & 0 & -1 & -1 & 33.6 \\
6 & 1 & 0 & 1 & 91.4 \\
7 & 0 & 0 & 0 & 63.4 \\
8 & 1 & 1 & 0 & 91.7 \\
9 & -1 & 1 & 0 & 10.9 \\
10 & 0 & 0 & 0 & 76.4 \\
11 & -1 & 0 & 1 & 10.7 \\
12 & 1 & -1 & 0 & 58.5 \\
13 & 0 & 1 & 1 & 61.9 \\
14 & 0 & 1 & -1 & 40.4 \\
\hline
\end{tabular}

\section{Results}

Plackett-Burman design(PB)

The significance of seven factors (potato extract concentration, glucose concentration, temperature, $\mathrm{pH}$, incubation period, inoculum size and aeration) on the production of bioactive compounds by Chaetosphaeronema sp. (KY321184) was investigated by PB design. The analysis depends on the inhibition percent exerted by the trails against Staphylococcus aureus ATCC 25923 (Table 2) as the main response. It is found that, potato extract concentration, glucose concentration, temperature, $\mathrm{pH}$, inoculum size and aeration are significant model terms $(\mathrm{P}<$ $0.05)$. The effect, standard error, $P$ value, and significance of each model term were represented in Table 5. Only potato extract concentration, glucose concentration and inoculum size were found to have a positive significant effect on the bioactive compounds production but temperature, $\mathrm{pH}$, aeration were found to negatively affect the process and that was illustrated in Pareto chart (Fig. 1). The ANOVA results showed that, the model $\mathrm{P}$ - value $=0.0103$, Table 6 . Correlation coefficient $\left(\mathrm{R}^{2}\right)$ value equals 0.9981 and the adjusted $\mathrm{R}^{2}$ value equals 0.9877 .

TABLE 5. Statistical analysis of effects of tested factors on bioactive compounds production by PBD.

\begin{tabular}{lccccc}
\hline Variable & Symbol & Effect (Coefficient) & Standard error & P value & Significance \\
\hline Potato extract conc. & $\mathrm{A}$ & 6.49 & 0.73 & 0.0125 & Significant \\
Glucose conc. & $\mathrm{B}$ & 6.92 & 0.73 & 0.0110 & Significant \\
Temperarure & $\mathrm{C}$ & -6.78 & 0.73 & 0.0115 & Significant \\
pH & $\mathrm{D}$ & -9.79 & 0.73 & 0.0056 & Significant \\
Incubation period & $\mathrm{E}$ & -1.79 & 0.73 & 0.1345 & Non-significant \\
Inoculum size & $\mathrm{F}$ & 7.41 & 0.73 & 0.0097 & Significant \\
Aeration & $\mathrm{G}$ & -4.06 & 0.73 & 0.0311 & Significant \\
\hline
\end{tabular}




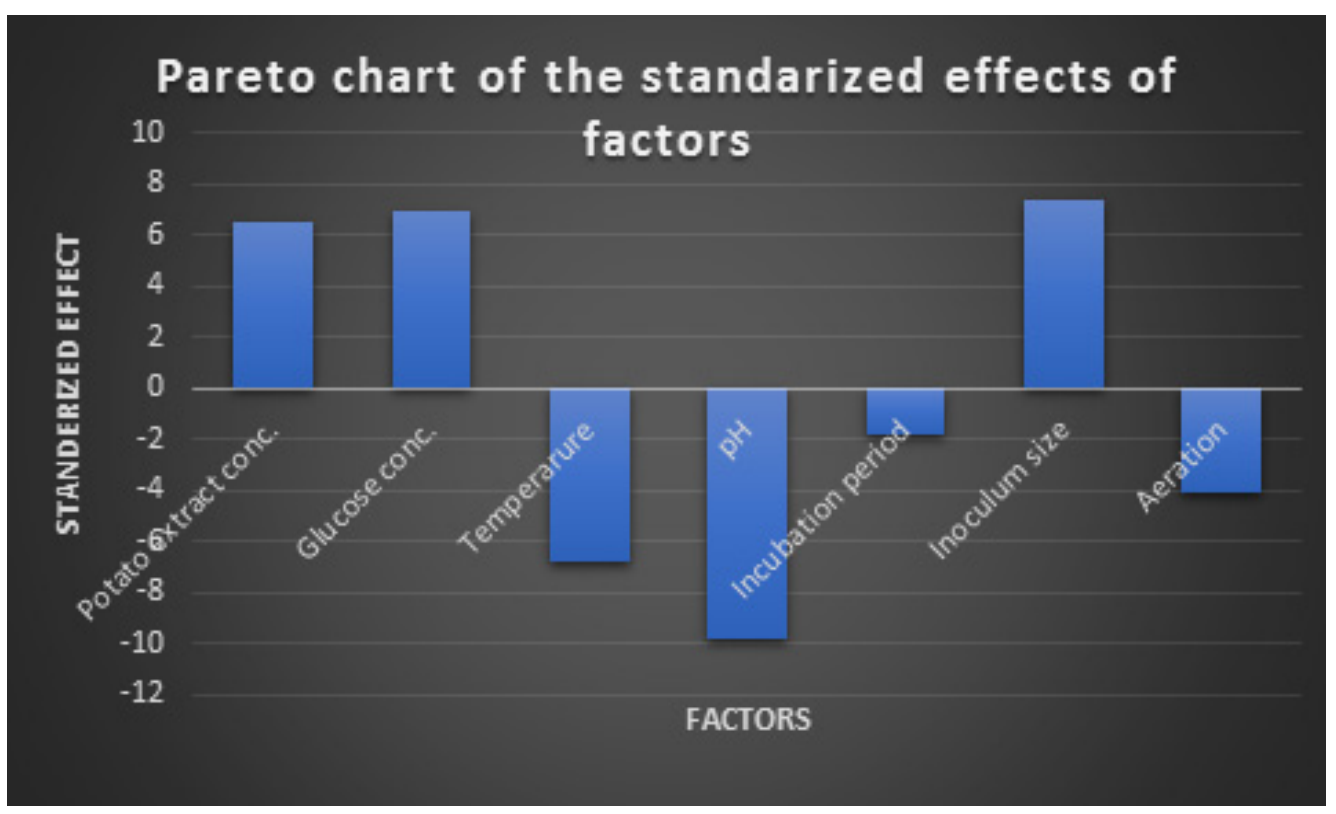

Fig. 1. Pareto chart showing the effect of different factors on bioactive compounds production by Chaetosphaeronema sp. (KY321184) according to Plackett-Burman design analysis.

TABLE 6. Regression statistics and model P-value for PBD.

\begin{tabular}{ll}
\hline $\begin{array}{l}\text { Model P } \\
\text { value }\end{array}$ & $\mathbf{0 . 0 1 0 3}$ \\
\hline $\begin{array}{l}\text { Model } \\
\mathrm{R}^{2}\end{array}$ & 0.9981 \\
$\begin{array}{l}\text { Model } \\
\text { adjusted }\end{array}$ & \\
$\mathrm{R}^{2}$ & 0.9877 \\
\hline
\end{tabular}

\section{Box-Behnken design(BBD)}

Based on the Plackett-Burman design results, response surface methodology using BoxBehnken design was employed to determine the optimal levels of the three significant factors positively affecting the bioactive compounds production (potato extract concentration, glucose concentration and inoculum size) to enhance the production process. The analysis depends on the inhibition percent exerted by the trails against Staphylococcus aureus ATCC 25923 as the main response (Table 4). The ANOVA analysis of model (Table 7) showed that, the model P-value was 0.0018 , the model F-value was 35.48 and the Lack of Fit is not significant (The "Lack of Fit F-value" was 0.35). Moreover, it has been reported that, $\mathrm{A}, \mathrm{B}, \mathrm{A}^{2}, \mathrm{~B}^{2}$ are significant model terms where $\mathrm{P}<0.05$. The model correlation coefficient $\left(\mathrm{R}^{2}\right)$ value equals 0.9876 while the adjusted $\mathrm{R}^{2}$ equals 0.9598 and the predicted $\mathrm{R}^{2}$ was 0.8745
(Table 8). The second-order polynomial equation estimated by the model regression analysis was as the following;

$$
\begin{gathered}
\text { Inhibition percent }=69.90+37.54 \mathrm{~A}+10.22 \\
\mathrm{~B}+3.00 \mathrm{C}+5.61 \mathrm{AB}+0.050 \mathrm{AC}+6.05 \mathrm{BC}- \\
10.77 \mathrm{~A}^{2}-18.82 \mathrm{~B}^{2}-9.38 \mathrm{C}^{2}
\end{gathered}
$$

where $\mathrm{A}, \mathrm{B}$ and $\mathrm{C}$ are the coded factors of potato extract concentration, glucose concentration and inoculum size, respectively. The main effect of factors and the interaction between them are illustrated by the perturbation and the threedimensional response plots. Perturbation plot (Fig. 2) shows the main effect of factors on bioactive compounds production. The plot showed that potato extract has the major effect followed by the glucose concentration. The three-dimensional response plots (Fig. 3, 4 and 5) were obtained using two factors, while keeping the other factor set at the zero level (intermediate value) to evaluate both the main and the interactive effects of factors. There was insignificant mutual interaction between the tested factors. It is observed that, the increase in potato extract concentration leads to an increase in bioactive compounds production but the increase in glucose concentration above $15 \mathrm{gL}^{-1}$ has inhibitory effect. The maximum bioactive compounds production (which yields the maximum inhibition percent) was calculated by the aid of Design Expert's numerical optimization 
which predicts to be $98.28 \%$ when potato extract, glucose concentrations and inoculum size equal $190.23 \mathrm{gL}^{-1}, 14.56 \mathrm{gL}^{-1}$ and 5.16, respectively (Fig.

TABLE 7. Statistical analysis of effects of tested factors on bioactive compounds production by BBD.

\begin{tabular}{lcccc}
\hline Variable & Effect (coefficient) & Standard error & P-value & Significance \\
\hline $\mathrm{A}$ & 37.54 & 2.33 & $<0.0001$ & Significant \\
$\mathrm{B}$ & 10.22 & 2.33 & 0.0118 & Significant \\
$\mathrm{C}$ & 3.00 & 2.33 & 0.2666 & Non-significant \\
$\mathrm{AB}$ & 5.61 & 3.29 & 0.1632 & Non-significant \\
$\mathrm{AC}$ & 0.050 & 3.92 & 0.9886 & Non-significant \\
$\mathrm{BC}$ & 6.05 & 3.29 & 0.1397 & Non-significant \\
$\mathrm{A}^{2}$ & -10.77 & 3.68 & 0.0429 & Significant \\
$\mathrm{B}^{2}$ & -18.82 & 3.68 & 0.0069 & Significant \\
$\mathrm{C}^{2}$ & -9.38 & 3.68 & 0.0632 & Significant \\
Model & 69.90 & 4.65 & 0.0018 & Significant \\
\hline
\end{tabular}

$\mathrm{A}=$ Potato extract conc., $\mathrm{B}=$ Glucose conc., $\mathrm{C}=$ Inoculum size..

TABLE 8. Regression statistics for BBD.

\begin{tabular}{lc}
\hline Model $\mathbf{R}^{2}$ & $\mathbf{0 . 9 8 7 6}$ \\
\hline $\begin{array}{l}\text { Model } \\
\text { adjusted } \mathrm{R}^{2}\end{array}$ & 0.9598 \\
$\begin{array}{l}\text { Model } \\
\text { predicted }\end{array}$ & 0.8745 \\
$\mathrm{R}^{2}$ & \\
\hline
\end{tabular}

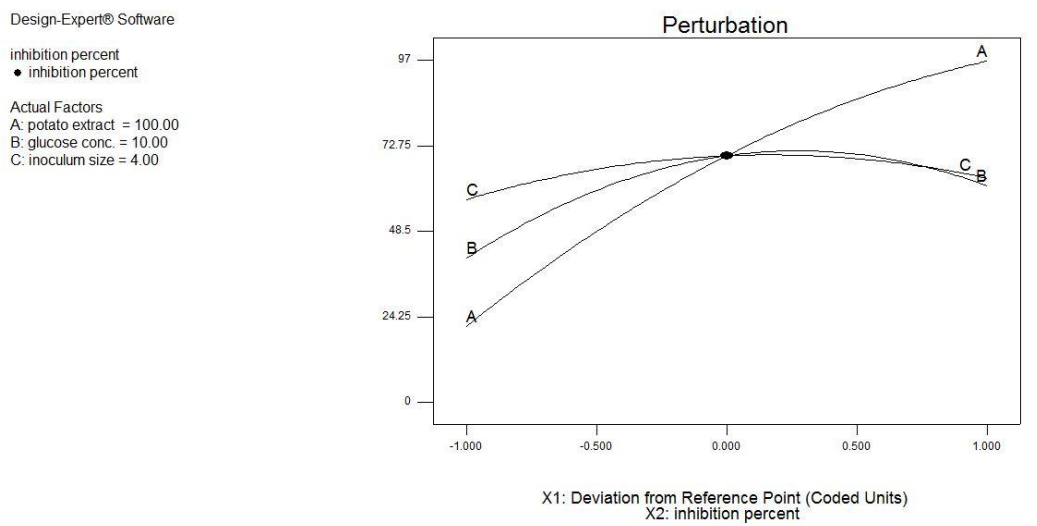

Fig. 2. Perturbation plot showing the main effect of: $A=$ Potato extract conc., $B=$ Glucose conc., $C=$ Inoculum size on bioactive compounds production (\% inhibition).
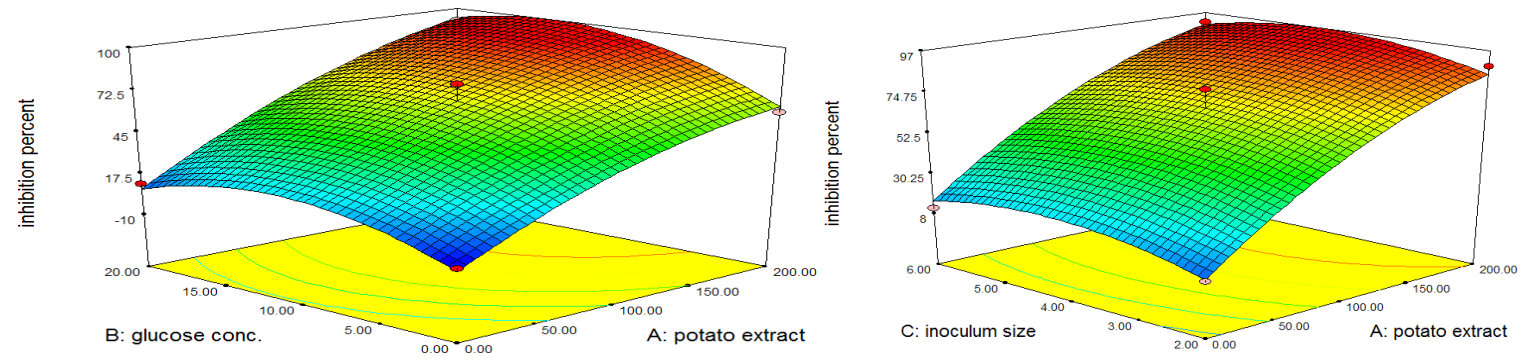

Fig. 3. 3-D. Response surface plot representing the interaction between the glucose conc. and potato extract conc. on bioactive compounds production (\%inhibition).

Fig. 4. 3-D. Response surface plot representing the interaction between the inoculum size and potato extract conc. on bioactive compounds production (\%inhibition). 


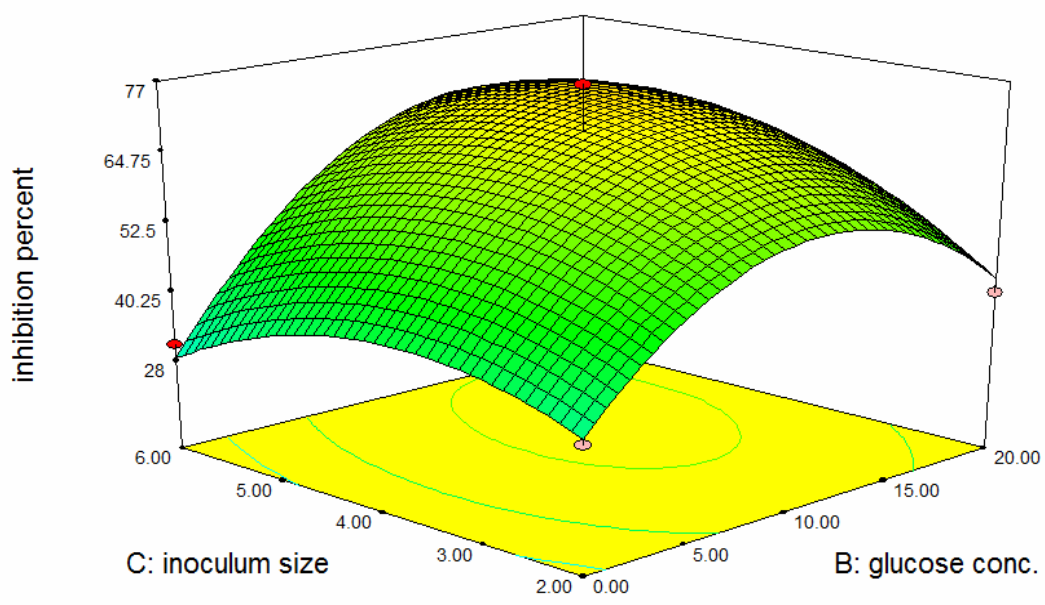

Fig. 5. 3-D. Response surface plot representing the interaction between the inoculum size and glucose conc. on bioactive compounds production (\%inhibition).

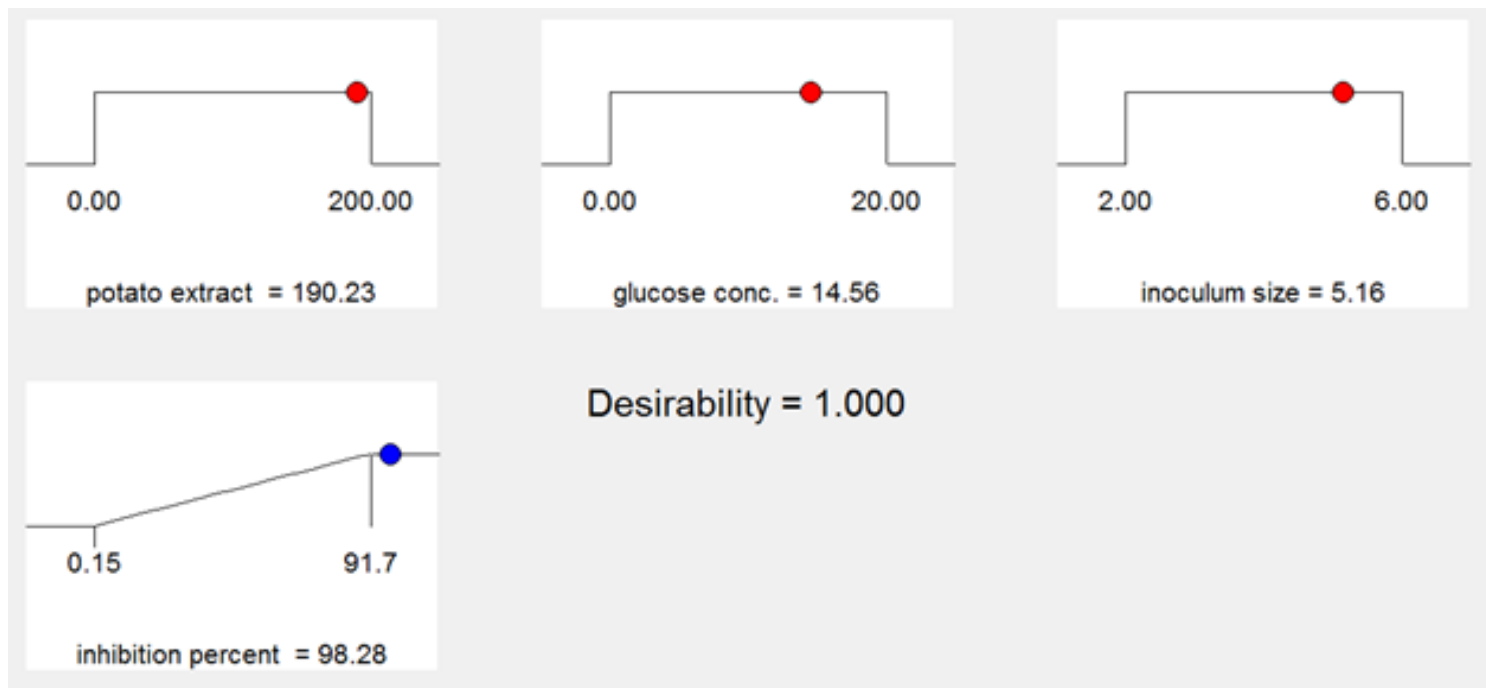

Fig. 6. Predicted solution for maximum bioactive compounds production (maximum inhibition percent) by BBD numerical optimization.

\section{Validation of model}

The approximated values of the previous predicted levels were tested experimentally as a check points for model validation. It is reported that, inhibition percent of $94.1 \%$ was obtained when the potato extract, glucose concentrations and inoculum size were $190 \mathrm{gL}^{-1}, 15 \mathrm{gL}^{-1}$ and 5 discs, respectively, giving a deviation of $4.3 \%$ and $5.3 \%$ from the predicted values of Design Expert model and Excel solver, respectively (Table 9).
Chemical analysis for PB trails products

It has been observed that, the different trails of PB design stimulated the production of different compounds, TLC chromatogram (Fig. 7). Moreover, trail number 15 was reported to stimulate the production of a bioactive compound in a considerable pure form. HPLC chromatogram for this trail showed one major beak corresponding to this compound (Fig. 8) and the general chemical identity was elucidated by ${ }^{1}$ HNMR (Fig. 9). 
TABLE 9. Model validation results (predicted and actual values for maximizing the main response).

\begin{tabular}{|c|c|c|c|c|c|}
\hline \multirow[b]{2}{*}{ Method } & \multicolumn{3}{|c|}{ Variable level } & \multirow[b]{2}{*}{$\begin{array}{c}\text { Response } \\
\text { (\% inhibition) }\end{array}$} & \multirow[b]{2}{*}{ Deviation } \\
\hline & $\begin{array}{c}\text { Potato } \\
\text { extract } \\
\text { conc. }\left(\mathrm{gL}^{-1}\right)\end{array}$ & $\begin{array}{c}\text { Glucose } \\
\text { conc. } \\
(\text { gL-1) }\end{array}$ & $\begin{array}{l}\text { Inoculum } \\
\text { size* }\end{array}$ & & \\
\hline Design Expert model prediction & 190.23 & 14.56 & 5.16 & 98.28 & $4.3 \%$ \\
\hline Excel solver prediction & 193.3 & 15.5 & 4.7 & 99.4 & $5.3 \%$ \\
\hline Experimental value (tested/actual) & 190 & 15 & 5 & 94.1 & \\
\hline
\end{tabular}

*Inoculum size $=$ Fungal disc diameter $=0.8 \mathrm{~cm}$.

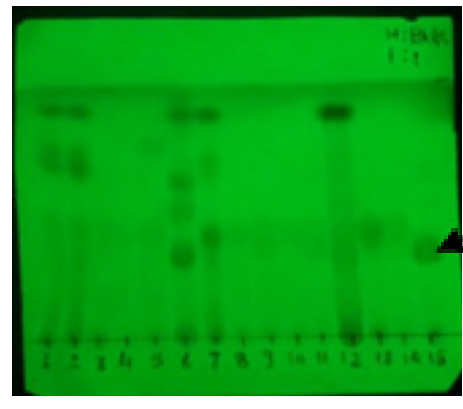

Under short UV

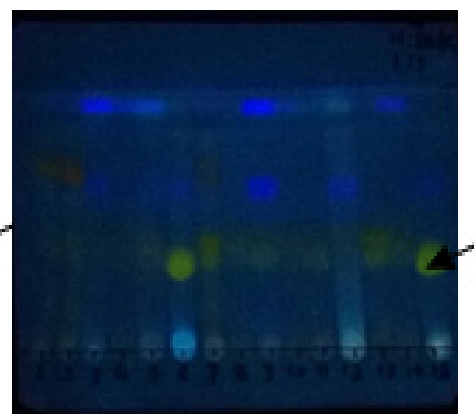

Under long UV

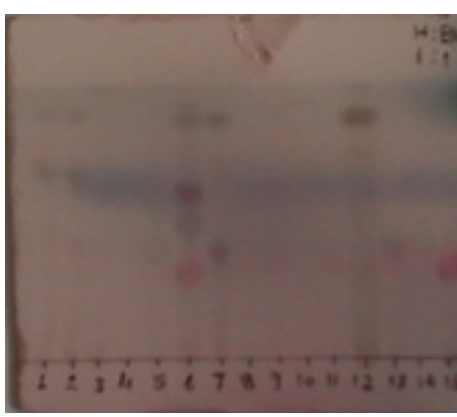

Sprayed with p-anisaldehyde agent

Fig. 7. TLC chromatogram of PB trails

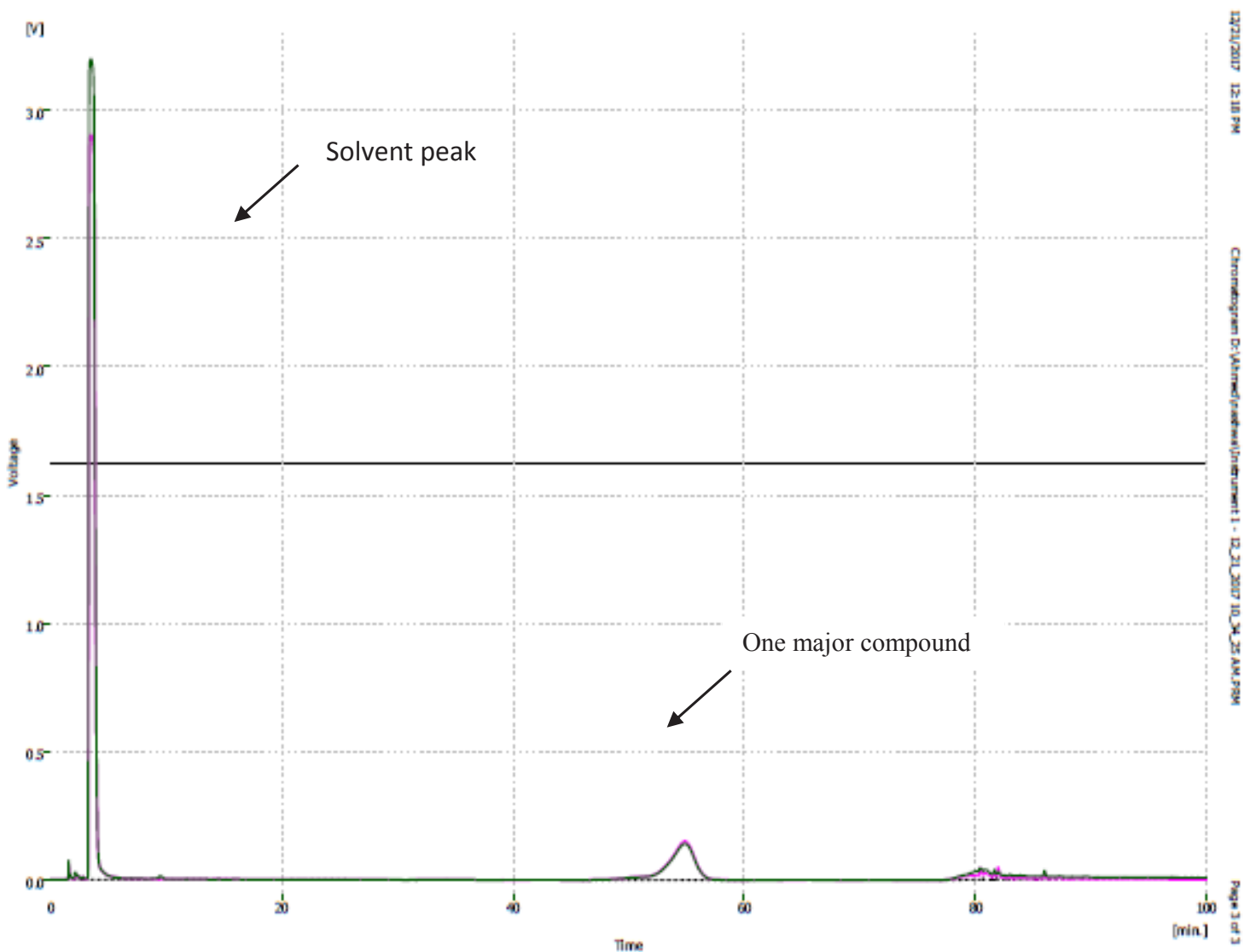

Fig. 8. HPLC chromatogram of PB trail number 15. 


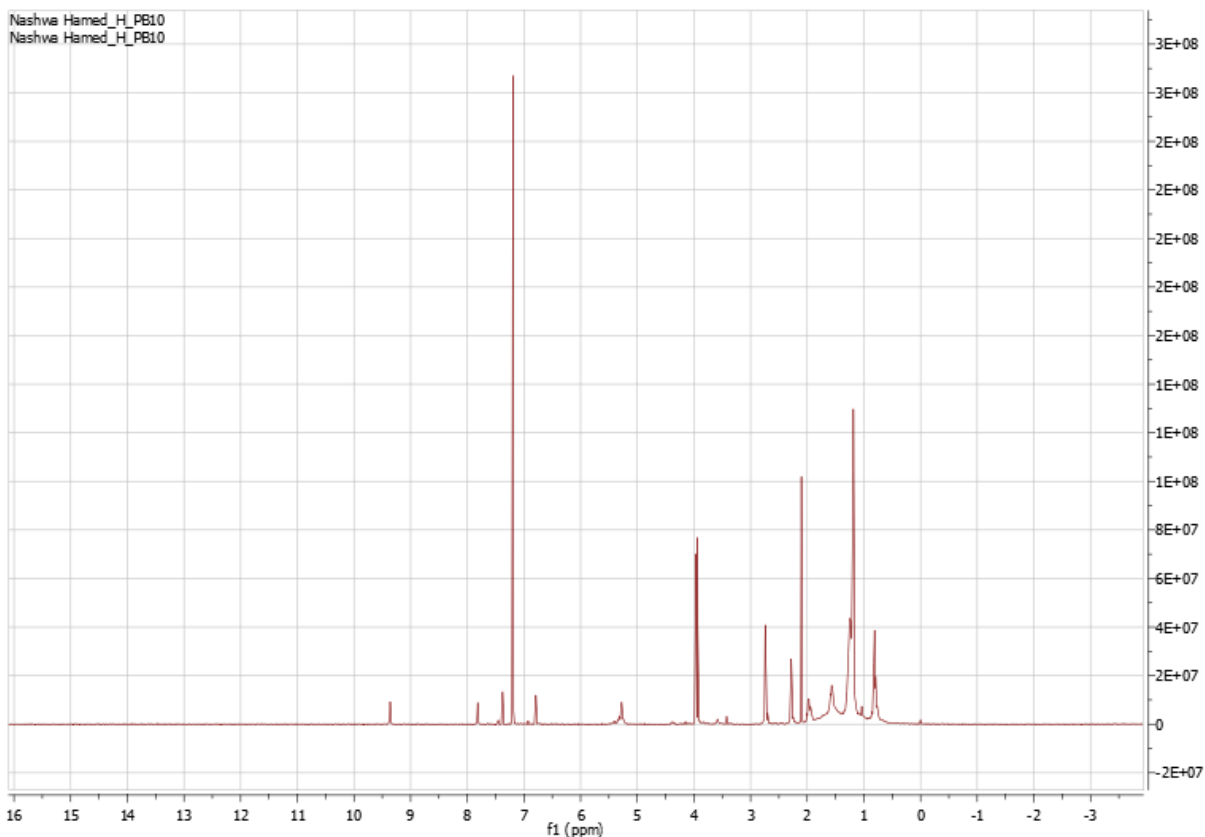

Fig. 9. ${ }^{1} \mathrm{HNMR}$ for compound produced in trail number 15 in PBD.

\section{Discussion}

Endophytic fungi have been characterized as a reliable source for promising bioactive compounds. The optimization of fermentation conditions for these fungi will play a role in the production of such compounds by an economically effective method. Experimental design methods for optimization process represent competitive and more efficient methods than the traditional 'one factor at time' method. The first step in this optimization study was a fast screen for the fermentation factors to determine the factors significantly affecting the bioactive compounds production process. That was maintained by employing Plackett-Burman (PB) experimental design. PB method has been introduced since 1946, it represents an economically approach that determines the main effects of factors (Analytical Methods Committee, 2013). The ANOVA results showed that the employed model was highly significant where the model P-value equals 0.0103 . Correlation coefficient $\left(\mathrm{R}^{2}\right)$ value equals 0.9981 which implies that the model equation could explain $99.81 \%$ of the total variation which suggested a good agreement between predicated values and experimental data. $\mathrm{R}^{2}$ is the coefficient of variance of response under test and whose values are always between 0 and 1 ; closer the value of $\mathrm{R}^{2}$ to 1 , the stronger is the statistical model and better is the prediction (Baadhe et al., 2014). The adjusted $\mathrm{R}^{2}$ value was 0.9877 . The adjusted $\mathrm{R}^{2}$ value corrects the $\mathrm{R}^{2}$ value for the sample size and for the number of terms in the model (Baadhe et al., 2014). That value of the adjusted $\mathrm{R}^{2}$ is also good, supporting the significance of this developed model. According to the model results, potato extract concentration, glucose concentration, temperature, $\mathrm{pH}$, inoculum size and aeration are significant model terms in antibacterial compounds production by Chaetosphaeronema sp. (KY321184). However, only potato extract concentration, glucose concentration and inoculum size were found to have a positive significant effect on the production process. Based on these results, Box-Behnken design was employed as a response surface methodology (RSM) method, to determine the optimal levels of these three factors to enhance the production process.

Response surface methodology (RSM) answers the question of how to select the levels for the applied factors to obtain the desirable value of the response in a reduced number of experiments (Bai et al., 2015). Moreover, it has been widely used to evaluate and understand the interactions between the different process parameters (Baadhe et al., 2014). Box-Behnken design is a RSM technique which has been widely studied by many researchers as an established and promising method for the optimization and formulation of various types 
of processes (Ding et al., 2016). The ANOVA analysis of the employed model showed that, the model was significant where the model P- value was 0.0018 , the model $\mathrm{F}$-value was 35.48 and the Lack of Fit is not significant (The "Lack of Fit F-value" was 0.35 ). The model correlation coefficient $\left(\mathrm{R}^{2}\right)$ value equals 0.9876 while the adjusted $R^{2}$ equals 0.9598 which reflects the very high correlation and supports the significance of model. The Predicted $\mathrm{R}^{2}$ was 0.8745 which is in reasonable agreement with the Adjusted $\mathrm{R}^{2}$.

According to results of this model, potato extract concentration and glucose concentration are significant model terms in bioactive compounds production by Chaetosphaeronema sp. (KY321184) where potato extract has the major effect followed by the glucose concentration. The increase in potato extract concentration leads to an increase in bioactive compounds production but the increase in glucose concentration above $15 \mathrm{gL}^{-1}$ has inhibitory effect. There was insignificant mutual interaction between the tested factors.

Design Expert numerical optimization predicted the maximum bioactivity to be $98.28 \%$ when potato extract, glucose concentrations and inoculum size equal $190.23 \mathrm{gL}^{-1}, 14.56 \mathrm{gL}^{-1}$ and 5.16 fungal discs, respectively, the calculation by Excel solver predicts the maximum inhibition percent to be $99.4 \%$ when potato extract, glucose concentrations and inoculum size equal 193.3 $\mathrm{gL}^{-1}, 15.5 \mathrm{gL}^{-1}$ and 4.7 fungal discs, respectively. Thus, the approximated values of these predicted levels were tested experimentally as a check points for model validation. When potato extract, glucose concentrations and inoculum size were $190 \mathrm{gL}^{-1}, 15 \mathrm{gL}^{-1}$ and 5 fungal discs, respectively, the inhibition percent of $94.1 \%$ was obtained giving a deviation of $4.3 \%$ and $5.3 \%$ from the predicted values of Design Expert model and Excel solver, respectively and that is considered as an acceptable error range.

Apart from the optimization aim, it has been observed that, the different trails of Plackett-Burman model have stimulated the production of different compounds and one of them was produced in a considerable pure form (trail number 15) as indicated from the HPLC chromatogram. That reflects the possibilities of utilizing such statistical models in modifying the production pattern of bioactive compounds by microorganisms trying to produce them in a partially pure form to save the cost and the effort exerted in the purification process.

\section{Conclusion}

Endophytic fungi have been characterized as a promising source for bioactive compounds. The optimization of fermentation conditions for these fungi will play a role in the production of such compounds by an economically effective method. Experimental design methods for optimization process represent a competitive and more efficient methods than the traditional 'one factor at time' method where the experimental design methods not only estimate the effects of many factors and optimize their levels using a fewer number of experiments but also can illustrate the interaction between them. Moreover, in the present study the trails of Plackett-Burman design have been found to stimulate the production of different bioactive compounds. Some of these compounds are produced in a partially pure form. That represents an initial guide for more studies in this point to evaluate the effectiveness of $\mathrm{PB}$ design runs in modifying the production pattern of bioactive compounds by microorganisms.

\section{Reference}

Analytical Methods Committee, AMCTB No 55 (2013) Experimental design and optimization (4) 'PlackettBurman designs'. Anal. Methods, 'The Royal Society of Chemistry', Vol. 5, pp. 1901-1903.

Anderson, M.J. and Whitcomb, P.J. (2004) "Screening Process Factors in the Presence of Interactions". Stat-Ease, Inc.

Baadhe, R.R., Mekala, N.K., Parcha, S.R. and Devi, Y.P. (2014) Optimization of amorphadiene production in engineered yeast by response surface methodology. Biotech. 4, 317-324.

Bai, Y., Saren, G. and Huo, W. (2015) Response surface methodology (RSM) in evaluation of the vitamin C concentrations in microwave treated milk. J. Food Sci. Technol. 52(7), 4647-4651.

Chandra, S. (2012) Endophytic fungi "novel sources of anticancer lead molecules". Appl. Microbiol. Biotechnol. 95, 47-59.

Ding, Y., Zheng, J., Xia, X., Ren, T. and Kan, J. 
(2016) Box-Behnken design for the optimization of nanoscale retrograded starch formation by highpower ultrasonication. LWT-Food Science and Technology, 67, 206-213.

Garyalis, S., Kumar, A. and Reddy, M.S. (2013) Taxol production by an endophytic fungus Fusarium redolens isolated from Himalayan yew. Journal of Microbiology and Biotechnology, 23(10), 13721380.

Jose, P.A., Sivakala, K.K. and Jebakumar, S.R.D. (2013) Formulation and statistical optimization of culture medium for improved production of antimicrobial compound by Streptomyces sp. JAJ06. International Journal of Microbiology, Vol. 2013, Article ID 526260 .

Kumar, S., Aharwal, R.P., Shukla, H., Rajak, R.C. and Sandhu, S.S. (2013) Endophytic fungi as a source of antimicrobials bioactive compounds. World Journal of Pharmaceutical Sciences, 3(2), 1179-1197.

Li, X., Xu, T., Ma, X., Guo, K., Kai, L., Zhao, Y. and Ma, Y. (2008) Optimization of culture conditions for production of cis-epoxysuccinic acid hydrolase using response surface methodology. Bioresource Technology, 99(13), 5391-5396.

Moghannem, S.A.M., Farag, M.M.S., Shehab, A.M. and Azab, M.S. (2017) Media optimization for exopolysaccharide producing Klebsiella oxytoca KY498625 under varying cultural conditions. International Journal of Advanced Research in Biological Sciences, 4(3), 16-30.
Quinn, G.P. and Keough, M.J. (2002) "Experimental Design and Data Analysis for Biologists". Cambridge University Press, Chapter 9, p. 223.

Rakić, T., Jančić-Stojanović, B., Malenović, A., Ivanović, D. and Medenica, M. (2012) Demasking large dummy effects approach in revealing important interactions in Plackett-Burman experimental design. Journal of Chemometrics, 26, 518-525.

Stone, J.K., Polishook, J.D. and White, J.F. (2004) "Endophytic Fungi, Biodiversity of Fungi", Elsevier Academic Press, Burlington, p. 242.

Stowe, R.A. and Mayer, R.P. (1966) Efficient screening of process variables. Industrial and Engineering Chemistry, 58(2), 36-40.

Talukdar, S., Talukdar, M., Buragohain, M., Yadav, A., Yadav, R.N.S. and Bora, T.C. (2016) Enhanced candicidal compound production by a new soil isolate Penicillium verruculosum $\mathrm{MKH7}$ under submerged fermentation. BMC Microbiology, 16, 288.

Zacharis, C.K. and Tzanavaras, P.D. (2004) Reviews in pharmaceutical and biomedical analysis. Chapter 10, "Pressurized Liquid Extraction in Phytochemical Analysis", pp. 135. Bentham Science Publishers.

(Received 27/ 2 /2018; accepted 23 / 4 /2018) 


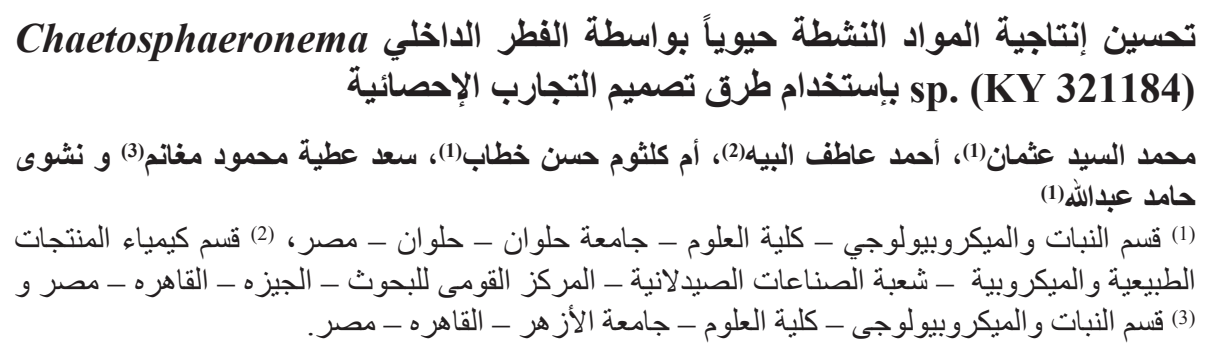

تهدف هذه الدراسة إلى تحسين إنتاجية الفطر Chaetosphaeronema sp. (KY321184) (احد الفطريات الداخلية المعزولة من نبات Nepeta septemcrenata) للمو اد النثطة حيوياً. تم إستخدام الطرق الإحصائية

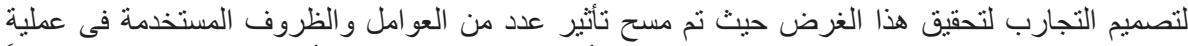

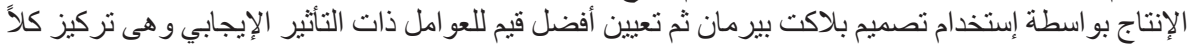

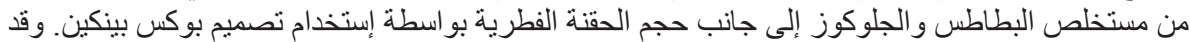

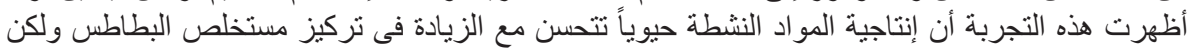

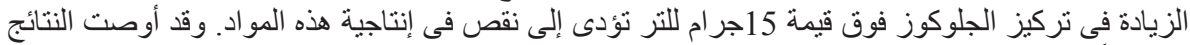

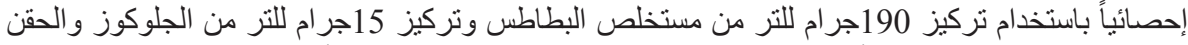

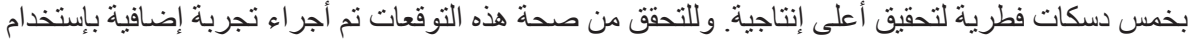

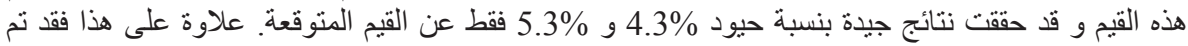

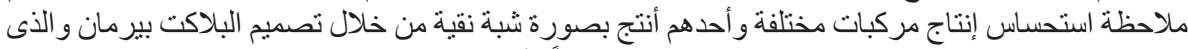

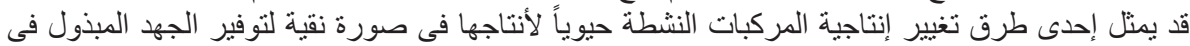
عمليات التنقية. 